Original Article

\title{
ANTI TUBERCULAR DRUGS INDUCED HEPATOTOXICITY IN A NEW TERTIARY CARE HOSPITAL OF A TRIBAL DISTRICT OF ODISHA
}

\author{
MANAS RANJAN NAIK ${ }^{1}$, MANORANJAN DASH ${ }^{2}$, BIBHU PRASAD BEHERA ${ }^{3 *}$, TRUPTI REKHA SWAIN ${ }^{4}$
}

${ }^{1}$ Department of Pharmacology, SLN Medical College and Hospital, Koraput, ${ }^{2}$ Department of TB and Chest, SCB Medical College and Hospital, Cuttack, ${ }^{3 *}$ Department of Internal Medicine, SLN Medical College and Hospital, Koraput, ${ }^{4}$ Department of Pharmacology, SLN

Medical College AND Hospital, Koraput

Email: drbibhu1111@yahoo.com

Received: 05 Jan 2021, Revised and Accepted: 26 Feb 2021

\begin{abstract}
Objective: India accounts for about one-fourth of the global TB burden. WHO TB statistics for India for 2018 gives an estimated incidence fig. of 2.69 million cases (199 per one lakh population). Drug-induced Hepatotoxicity is responsible for significant morbidity and mortality of the TB patient if these drugs continued after symptoms of hepatotoxicity develop. Whether the hepatotoxicity is due to individual drugs or due to additive effects is still unclear. The management therapy for TB patients with anti-TB DIH is imperative to ensure successful TB treatment and not recurrence DIH. Aim of the current study is to find out the pattern of Liver enzyme raised after antitubercular therapy in the tribal population of Koraput district where different phylogenetic populations reside where clinically it was observed by the physician little early onset of hepatotoxicity than national and international data.
\end{abstract}

Methods: A prospective study was done after clearance from the Institutional Ethical Committee, Saheed Laxman Nayak Medical College, Koraput, from January 2019 to December 2019. Patients with>15 y of age with pulmonary and extrapulmonary tuberculosis with normal liver enzymes were included. Patients having abnormal liver enzymes before treatment, seropositive TB patients with human immunodeficiency virus infection, pregnant ladies and children< $15 \mathrm{y}$ of age were excluded.

Results: Out of 922 patients in total; 4.78\% (44) tuberculosis patients developed anti TB DIH. 68.18\% (30) patients are below 50 y of age and 31.82\% (14) are above 50 y of age group among TB patients with DIH. Age has no statistically significant influence on the occurrence of anti-TB DIH, but there is a statistically significant influence of sex on the occurrence of anti TB DIH. The mean occurrence of anti TB DIH is $18 \pm 18.16 \mathrm{~d}$. One case of anti TB DIH patients shows signs and symptoms as early as on day 6th. The commonest symptoms are nausea and vomiting in $64 \%$ of patients who developed DIH. Interruption of ATT after DIH occurred in $79.54 \%$ of patients with recurrence in only $9.9 \%$ of patients after the reintroduction of ATT.

Conclusion: Anti TB DIH mostly occurred between 7-28 d of starting the ATT in this geographical region. The duration of the anti TB ATT regimen is prolonged due to DIH. We recommend that all patients should have LTs $2 \mathrm{w}$ after starting ATT, even if asymptomatic.

Keywords: Tuberculosis, Drug-induced hepatotoxicity, Anti tubercular therapy induced, Drug-induced liver injury

(C) 2021 The Authors. Published by Innovare Academic Sciences Pvt Ltd. This is an open access article under the CC BY license (https://creativecommons.org/licenses/by/4.0/) DOI: https://dx.doi.org/10.22159/ijpps.2021v13i4.40704. Journal homepage: https://innovareacademics.in/journals/index.php/ijpps.

\section{INTRODUCTION}

Tuberculosis (TB) continues to remain as one of the most significant infectious diseases across much of the world. It carries an alarming socioeconomic burden on the individual and society. Tuberculosis remains an important cause of ill health and is one of the top 10 causes of death universally. An estimated 10.0 million with a range of 9.0-11.1 million people fell ill with tuberculosis in 2018 [1]. In 2018, geographically, most tuberculosis cases were in the World Health Organization (WHO) regions of South-East Asia (44\%), Africa $(24 \%)$ and the Western Pacific (18\%). India (27\%), China (9\%), Indonesia (8\%), the Philippines (6\%), Pakistan (6\%), Nigeria (4\%), Bangladesh (4\%), and South Africa (3\%) accounted for two-thirds of the universal total [1]. India accounts for about one-fourth of the global TB burden [2]. It is estimated that about $40 \%$ of the Indian population is infected with Mycobacterium tuberculosis; the vast majority of those have latent tuberculosis rather than the disease. For 2018, WHO TB statistics for India give an estimated incidence fig. of 2.69 million TB cases (199 per one lakh population) [3]. 50303 and 71131 patients are notified with TB in both the public and private sector in ODISHA in 2018 and 2017 respectively [3].

Revised National Tuberculosis Control Programme (RNTCP) Anti Tubercular Therapy (ATT) is the only cost-effective strategy to treat pulmonary tuberculosis as recommended by WHO. Drug-Induced Hepatotoxicity (DIH) is important and commonly occurring adverse drug reaction (ADR) with Isoniazid, Rifampicin, and Pyraniazide. Due to anti TB drug treatment, the reported incidence of DIH due to
anti-TB standards varied between $2.0 \%$ and $28.0 \%$ depending on population differences and the definition of DIH [4]. A study in India showed that disturbed liver transaminases $(33.33 \%)$ were common in ADR observed from first-line anti-TB drugs. Nausea and vomiting, hepatitis, rash, headache, constipation, fever, flu-like syndrome, blurred vision and optic neuritis, metabolic disturbances including hyperglycemia, and diarrhea are the other ADRs included [5]. The percentage of patients with single and more than one ADR from first-line anti-TB drugs were $24.09 \%$ and $75.9 \%$, respectively, as shown by another study [4]. A higher risk of hepatotoxicity has been reported in Indian patients (6-9) than in their Western counterparts $(10-12)$. The causes for this higher rate of hepatotoxicity in Indian patients are indistinct. Anti TB DIH accounts for $7 \%$ of reported drug adverse effects, $2 \%$ of jaundice in hospitals, and approximately $30 \%$ of fulminant liver failure $[13,14]$.

Dissimilar suggestions have been made for monitoring liver tests (LTs) in patients on ATT by the American Thoracic Society (ATS) [15], the British Thoracic Society [16], and the European Respiratory Society (ERS) [17] with some favoring a risk factor-based approach. Singanayagam et al. compared the two approaches, judging in support of universal testing $2 \mathrm{w}$ into treatment [18]

The Drug-Induced Liver Injury (DILI) Expert Working Group [19] and DILIGEN study [20] use criteria based on ALT, ALP, and bilirubin to guide the stoppage of ATT. All expert recommendations comprise treatment cessation at ALT $>5 \mathrm{x}$ Upper Limit of Normal (ULN) or if the patient is icteric; ATS recommends cessation if ALT is 
3-5xULN and the patient reports symptoms including nausea, anorexia, vomiting, abdominal pain, and jaundice. Each advisory body has recommendations for treatment re-introduction when LTs have normalized; these either opine sequential re-introduction with incremental dose increase or re-introduction at full dosage [15-17].

Anti-tuberculosis drug-induced hepatotoxicity (anti-TB-DIH) may be a consequence of the direct toxicity of the primary compound, a metabolite, or from an immunologically mediated response, affecting hepatocytes, biliary epithelial cells, and/or liver vasculature $[15,21]$. Most types of anti-TB-DIH are attributable to metabolic idiosyncrasy due to the metabolites released or accumulated during the metabolic course. These hypersensitivity or metabolic reactions happen largely independent of the dose [22] The pathogenesis of DIH caused by Isoniazid is not well understood [23]. Hepatocyte necrosis, ballooning degeneration, and inflammatory infiltrate suggest dose-related toxicity [24]. Whether the hepatotoxicity is due to individual drugs or due to additive effects is still unclear.

DIH diminishes the efficiency of anti-TB management, may lead to non-adherence and can cause treatment failure, recurrence, or drug resistance [25]. DIH is responsible for major morbidity and mortality of tuberculosis patients if these therapies continued after symptoms of hepatotoxicity manifest [26]. The management therapy for TB patients with anti TB DIH is imperative to ensure successful TB treatment and not recurrence DIH.

\section{AIM OF THE STUDY}

So the aim of current study is to find out the pattern of Liver enzyme raised after ATT in the tribal population of Koraput district where different phylogenetic populations reside where clinically it was observed by the physician little early onset of hepatotoxicity than national and international data.

\section{MATERIALS AND METHODS}

A prospective study was done after clearance from Institutional Ethical Committee, Saheed Laxman Nayak Medical College, Koraput from January 2019 to December 2019. Patients' data were collected from the Department of TB and Chest and Medical Record Department SLNMCH. Patients' demographic data, co-morbidities, addictions, medications, signs and symptoms, details of ATT, time of DIH onset from the start of ATT, duration of withdrawal of ATT, timing of the reintroduction of ATT were collected. Investigations details like sputum for AFB, CBNAAT, Chest X-ray, Urea, Creatinine, Liver enzymes, Serum bilirubin, HIV, Hepatitis, CBC, FBS, HbA1c data also collected for evaluation and analysis. During the beginning of treatment for tuberculosis, those patients who had no abnormal liver functions were taken as study population, and patients with active TB without DIH were considered as control. DIH case was defined as per DILI Expert working Group and DILIGEN CRITERIA.

Monitoring of patients, who started ATT, was done every $7 \mathrm{~d}$ by evaluating Liver Function Tests and comparing with baseline values before treatment in those patients who developed symptoms of liver injury. If ATT was more than 3 times Upper Normal Limits with symptoms and 5 times ULN without symptoms, ATT was discontinued. In the case of severe tuberculosis patients, modified ATT regimens were continued. After Liver enzymes come to normal after treatment again ATT started under close supervision and monitoring of liver enzymes by TB and Chest Physician.

\section{Inclusion criteria}

- Patients with $>15$ y of age.

- Those patients with pulmonary and extrapulmonary tuberculosis with normal liver enzymes.

\section{Exclusion criteria}

- Patients having abnormal liver enzymes before treatment.

- TB patients with human immunodeficiency virus infection.

- Pregnant ladies and children $<15 \mathrm{y}$ of age.

\section{Statistical analysis}

The statistical analysis was done using the Statistical Package for Social Sciences (SPSS) version 21.0. Discrete variables were presented as frequency and percentages. Continuous variables were presented as means and standard deviation (SD) for unpaired data; a Student t-test was used to compare mean values (for two groups). A Chi-square test was used to determine the significant associations between categorical variables. P-value $<0.05^{*}$ was considered statistically significant and Pvalue $<0.001^{* *}$ was considered statistically very significant.

\section{RESULTS}

During the study period, a total of 922 patients were diagnosed with tuberculosis and given ATT in SLNMCH. Out of which 51.41\% (474) cases were pulmonary tuberculosis and $46.75 \%$ (431) cases were extrapulmonary tuberculosis; the rest 17 cases had no data about the site of the lesion. Out of 922 cases with tuberculosis, we included 44 tuberculosis patients with anti TB DIH $(4.78 \%)$ in our study that fulfills inclusion and exclusion criteria. They were compared with 44 TB patients without anti TB DIH who were taken as controls.

Table 1: Age distribution

\begin{tabular}{lllll}
\hline \multirow{2}{*}{ Age } & \multicolumn{2}{c}{ TB patients with DIH (n=44) } & \multicolumn{2}{c}{ TB patients without DIH (n=44) } \\
\cline { 2 - 4 } & f & \% & f & P-value \\
\hline$<50 \mathrm{y}$ & 30 & $68.18 \%$ & 32 & $72.73 \%$ \\
$>50 \mathrm{y}$ & 14 & $31.82 \%$ & 12 & $27.27 \%$ \\
\hline
\end{tabular}

Table 1 shows in our study population, $68.18 \%$ (30) patients are below $50 \mathrm{y}$ of age and $31.82 \%$ (14) are above 50 y of age group among TB patients with DIH. Age has no statistically significant ( $\mathrm{p}=$ 0.815) influence on the occurrence of anti-TB DIH [table 1], but there is statistically significant $(p=0.027)^{*}$ influence of sex on occurrence of anti TB DILI [table 2]. Table 2 show M: F ratio among TB patients without DIH is 3:1 whereas it is $1: 1$ among TB patients with DIH.

Table 2: Sex distribution

\begin{tabular}{lllll}
\hline Sex & \multicolumn{2}{l}{ TB patients with DIH (n=44) } & \multicolumn{2}{c}{ TB patients without DIH (n=44) } \\
\cline { 2 - 4 } & f & \% & f & P-value \\
\hline Male & 22 & $50 \%$ & 33 & $75 \%$ \\
Female & 22 & $50 \%$ & 11 & $25 \%$ \\
\hline
\end{tabular}

One case of anti TB DIH patients shows signs and symptoms as early as on day $6^{\text {th }}$ and confirmed by lab findings on day $7^{\text {th }}$; and the last case or delayed case detected on the $42^{\text {nd }}$ day of starting antitubercular drugs. The mean occurrence of anti TB DIH is $18 \pm 18.16 \mathrm{~d}$ [table 3]. The number of TB patients who developed DIH between $7^{\text {th }}$ to $28^{\text {th }}$ days is more $(62 \%)$. 
Table 3: Time of onset in tuberculosis patients with DIH

\begin{tabular}{ll}
\hline Onset of DIH & \\
\hline Min-max days & $6^{\text {th }}-42^{\text {nd }}$ day \\
mean \pm SD & $18 \pm 18.16 \mathrm{~d}$ \\
\hline
\end{tabular}

AST, ALT and total bilirubin tests have been conducted in all TB patients with anti-tubercular drugs. Initially, there is no significant difference in AST, ALT, and total bilirubin on day 0.

Table 4: Comparison of laboratory parameters of TB patients with anti TB DIH and without anti TB DIH

\begin{tabular}{llll}
\hline Laboratory parameters & \multicolumn{2}{l}{ TB patients with DIH (n=44) } & TB patients without DIH (n=44) \\
\cline { 2 - 3 } & In mean+SD & In mean+SD \\
\hline Hemoglobin $(\mathrm{gm} / \mathrm{dl})$ & $10.09 \pm 1.32$ & $11.09 \pm 1.62$ \\
Total bilirubin $(\mathrm{mg} / \mathrm{dl})$ & $1.87 \pm 1.25$ & $0.94 \pm 0.35$ & $0.002^{*}$ \\
Aspartate aminotransferase/AST(IU/l) & $246.97 \pm 22.45$ & $40.38 \pm 12.37$ \\
Alanine aminotransferase/ALT(IU/l) & $152.53 \pm 11.21$ & $41.64 \pm 13.52$ \\
\hline
\end{tabular}

Comparison between laboratory parameters of TB patients with anti-TB DIH and without anti TB DIH showed a statistically significant difference. Values are expressed as mean+SD.

Table 4 shows liver function tests conducted for tuberculosis patients at the beginning of diagnosis of DIH. The mean test result for hemoglobin, total bilirubin, AST, and ALT is $10.09 \pm 1.32 \mathrm{gm} / \mathrm{dl}$,
$1.87 \pm 1.25 \mathrm{mg} / \mathrm{dl}, 246.97 \pm 22.45 \mathrm{IU} / \mathrm{l}$, and $152.53 \pm 11.21 \mathrm{IU} / \mathrm{l}$, respectively; which are found to be statistically very significant when compared with the same parameters in TB patients without DIH.

Table 5: Impact of anti TB DIH on TB treatment of the patients ( $N=44)$

\begin{tabular}{lll}
\hline Impact of anti TB DIH & Number of anti-TB DIH patients (N=44) & F \\
\cline { 2 - 3 } & F & 35 \\
Stop all anti-tubercular drugs/interruption of ATT after DIH & 8 & $18.54 \%$ \\
Modified ATT/Substitution therapy (Streptomycin, Levofloxacin, Ethambutol) & $18 \%$ \\
No change in ATT/Treatment continue & 4 & $2.27 \%$ \\
Recurrence anti TB DIH & $9.09 \%$ \\
\hline
\end{tabular}

After diagnosis of anti-TB DIH, in 35 (79.54\%) patients, all antitubercular drugs are stopped; in 8 (18.18\%) patients, the substitution therapy with Streptomycin, Levofloxacin and Ethambutol (modified ATT) are given after withdrawn of anti-TB therapy [table 5]. In $1(2.27 \%)$ patient; there was no change in anti TB regimen and the treatment with ATT was continued. After treatment with hepatoprotective drugs in those 35 patients in whom ATT was stopped, there was an improvement in liver enzymes and signs and symptoms in all 35 patients after one month. But, in 4 $(9.9 \%)$ patients, recurrence of anti TB DIH occurs.

\section{DISCUSSION}

During the study period, out of 922 patients in total; $51.41 \%$ (474) cases were pulmonary tuberculosis and $46.75 \%$ (431) cases were extrapulmonary tuberculosis. Out of which, we included 44 tuberculosis patients with anti TB DIH (4.78\%) in our study that fulfills inclusion and exclusion criteria. Alu Abbra et al. study found the onset of anti TB DIH in 6.9\% of tuberculosis patients [27].

Age has no statistically significant $(p>0.05)$ influence on the occurrence of anti-TB DIH [table 1], but there is statistically significant $(\mathrm{p}<0.05)$ influence of sex on the occurrence of anti TB DIH [table 2] in our study. In Gronhagen et al. study, female was a risk factor for hepatotoxicity [28]. Maria et al. study showed that age and sex not statistically significant influences on the occurrence of anti-TB DIH [29]. With a different result, Buntoro et al. study showed that sex did not affect the increase in ALT level but age had an effect on the increase in ALT level in TB patients who were treated with first-line anti-TB drugs [30].

In our study, we found that lower $\mathrm{Hb}$, low body weight and alcohol consumption has a higher rise in liver enzymes. Gronhagen et al. study also found high alcohol intake as a risk factor for hepatotoxicity [28].

The commonest symptoms are nausea and vomiting in $64 \%$ of patients who developed DIH. Jaundice was found in $28 \%$ of the patients who developed DIH. 55\% had digestive symptoms and jaundice was the presenting complaint in $10 \%$ of patients in the Black et al. study [24].

If AST or ALT is more than 5 times the ULN value with or without symptoms and $>3$ times plus jaundice or hepatitis the ATT should be discontinued [15, 16, and 31]. In our study, anti TB drugs were discontinued in $79.54 \%$ of patients as they meet the abovementioned criteria. In $18.18 \%$ of patients, the increase in AST, ALT is not more than 5 times the ULN but in between 2 to 5 times without jaundice or hepatitis. So in these 8 patients, we substitute the recommended ATT with modified ATT Streptomycin, Levofloxacin, and Ethambutol. In one patient $(2.27 \%)$ there is no significant increase in liver enzymes so ATT is continued but under observation. $9.09 \%$ had a recurrence of DIH. These findings were very much similar to Maria et al. study, which found interruption in $78.9 \%$, substitution therapy in $15.8 \%$, no change of treatment in $2.27 \%$, and recurrence in $11.4 \%$ of anti TB DIH patients [29].

In our study, $62 \%$ of anti TB DIH occurred between $7^{\text {th }}$ to $28^{\text {th }}$ days of starting ATT which is quite earlier than other studies. In Alu Abbra et al. study, the onset of DIH in 53\% of patients was within 2 $\mathrm{w}$ [27]. The median time to DIH of $18+18.16 \mathrm{~d}$ is comparable with the Singanayagam et al. study and Alu Abbra et al. study [18,27] and indicates to us that all patients should have LTs $2 \mathrm{w}$ after starting ATT, even if asymptomatic. The improvement in liver enzymes started from day $10^{\text {th }}$ onwards up to day $25^{\text {th }}$ of withdrawal of ATT and after starting the hepatoprotective drug.

\section{CONCLUSION}

Anti TB DIH mostly occurred between 7-28 d of starting the ATT in this geographical region with a median time to DIH of $(18+18.16)$. Maximum patients who developed DIH respond to the hepatoprotective drug with ATT withdrawal of one month. In only $9.9 \%$ of patients, there is a recurrence of hepatotoxicity after reintroduction of ATT. The rest of the anti-TB DIH patients completed their anti TB treatment after recovery of one month successfully. But the duration of the anti TB ATT regimen is 
prolonged due to DIH. We recommend that all patients should have LTs $2 \mathrm{w}$ after starting ATT, even if asymptomatic.

\section{LIMITATIONS OF THE STUDY}

A more extensive study, including large number of patients and for longer period; with an appropriate clinical trial is required to arrive at a firm conclusion.

\section{ETHICAL APPROVAL}

The study was approved by Institutional Ethics Committee.

\section{FUNDING}

Nil

\section{AUTHORS CONTRIBUTIONS}

All the authors contributed equally in this research work. All authors read and approved the final manuscript.

\section{CONFLICT OF INTERESTS}

\section{Declared none}

\section{REFERENCES}

1. Global tuberculosis report; 2019. Geneva: World Health Organization; 2019. License: CC BY-NC-SA 3.0 IGO. Available from: https://creativecommons.org/licenses/by-nc-sa/3.0/igo. [Last accessed on 31 Dec 2020]

2. Burden of TB in India. Available from: https://tbfacts.org/tbindia/. [Last accessed on 31 Dec 2020]

3. TB Statistics India. Available from: https://tbfacts.org/tbstatistics-india/. Last accessed on 31 Dec 2020]

4. Siddiqui S, Baig MM, Jafer S, Ansari SF. Study on prevalence of adverse drug reactions in patients suffering from tuberculosis in a tertiary care hospital. Int J Pharm Pharm Sci 2016;8:375-7.

5. Verma R, Mahor GR, Shirvastava AK, Pathak P. Adverse drug reactions with first-line anti-tubercular drugs in a tertiary care hospital of central India: a study of clinical presentations, causality, and severity. Asian J Pharm Clin Res 2014;7:140-3.

6. Parthasarathy R, Sarma GR, Janardhanam B, Ramachandran P, Santha T, Sivasubramanian S, et al. Hepatic toxicity in south Indian patients during treatment of tuberculosis with shortcourse regimens containing isoniazid, rifampicin and pyrazinamide. Tubercle 1986;67:99-108.

7. Purohit SD, Gupta PR, Sharma TN, Gupta DN, Chawla MP. Rifampicin and hepatic toxicity. Indian J Tuberc 1983;30:107-9.

8. Taneja DP, Kaur D. Study on hepatotoxicity and other side effects of antituberculosis drugs. J Indian Med Assoc 1990;88:278-80.

9. Mehta S. Malnutrition and drugs: clinical implications. Dev Pharmacol Ther 1990;15:159-65.

10. Snider DE, Long MW, Cross FS, Farer LS. Six months isoniazid and rifampicin therapy for pulmonary tuberculosis: report of a United States Public Health Service cooperative trial. Am Rev Respir Dis 1984;129:573-9.

11. Dutt AK, Moers D, Stead WW. Short course chemotherapy for tuberculosis with mainly twice-weekly isoniazid and rifampicin: community physicians' seven-year experience with mainly outpatients. Am J Med 1984;77:233-42.

12. British Thoracic and Tuberculosis Association. Short course chemotherapy in pulmonary tuberculosis. Lancet 1975;i:11924.

13. S Chitturi, G Farrell. Drug-induced liver disease. In: ER Schiff, MF Sorrell, WC Maddrey. Eds. Schiff's Diseases of the Liver. $9^{\text {th }}$ ed. Lippincott, Williams and Wilkins, Philadelphia; 2002. p. 1059-128.
14. D Larrey. Epidemiology and individual susceptibility to adverse drug reactions affecting the liver, Semin. Liver Dis 2002;22:145-55.

15. Saukkonen JJ, Cohn DL, Jasmer RM, Schenker S, Jereb JA, Nolan CM, et al. ATS (American Thoracic Society) hepatotoxicity of antituberculosis therapy subcommittee. An official ATS statement: hepatotoxicity of antituberculosis therapy. Am J Respir Crit Care Med 2006;174:935-52.

16. Chemotherapy and management of tuberculosis in the United Kingdom: recommendations. Joint Tuberculosis Committee of the British Thoracic Society. Thorax 1998;53:536-48.

17. Migliori GB, Raviglione MC, Schaberg T, Davies PD, Zellweger JP, Grzemska M, et al. Tuberculosis management in Europe. Taskforce of the European Respiratory Society (ERS), the World Health Organisation (WHO) and the International Union against Tuberculosis and Lung Disease (IUATLD) Europe Region. Eur Respir J 1999;14:978-92.

18. Singanayagam A, Sridhar S, Dhariwal J, Abdel Aziz D, Munro K, Connell DW, et al. A comparison between two strategies for monitoring hepatic function during antituberculous therapy. Am J Respir Crit Care Med 2012;185:653-9.

19. Aithal GP, Watkins PB, Andrade RJ, Larrey D, Molokhia M, Takikawa $\mathrm{H}$, et al. Case definition and phenotype standardization in drug-induced liver injury. Clin Pharmacol Ther 2011;89:806-15.

20. Daly AK, Donaldson PT, Bhatnagar P, Shen Y, Peer I, Floratos A et al. HLA-B*5701 genotype is a major determinant of druginduced liver injury due to flucloxacillin. DILIGEN study; international sae consortium. Nat Genet 2009;41:816-9.

21. N Kaplowitz. Mechanisms of cell death and relevance to drug hepatotoxicity. In: N Kaplowitz, L DeLeve. Eds. DrugInduced Liver Disease, Marcel Dekker, New York; 2002. p. 85-95.

22. Federal Ministry of Health, Ethiopia. Guidelines for Clinical and Programmatic Management of TB, TB/HIV and Leprosy in Ethiopia. $5^{\text {th }}$ edition. Addis Ababa, Ethiopia; 2013.

23. Sharma SK, Mohan A. Anti-tuberculosis treatment-induced hepatotoxicity. In: Venkatraman GS. Editor. Medicine update. Vol. 14. Mumbai Association Physicians of India; 2004. p. 298-306.

24. Black M, Mitchell JR, Zimmerman HJ. Isoniazid associated hepatitis in 114 patients. Gastroenterology 1975;69:289-302.

25. Penghui S, Xia Y, Liu F, Wang X, Yuan Y, Hu D, et al. Incidence, clinical features and impact on anti-tuberculosis treatment of anti-tuberculosis induced liver injury (ATLI) in China. PLoS One 2011;6:7

26. Satyaraddi A, Velpandian T, Sharma SK, Vishnubhatla S, Sharma A, Sirohiwal A, et al. Correlation of plasma anti-tuberculosis drug levels with subsequent development of hepatotoxicity. Int J Tuberc Lung Dis 2014;18:188-95, i-iii.

27. Alu Abbara, Sarah Chitty, Jennifer K Roe. Drug induced liver injury from antituberculosis treatment: a retrospective study from a large TB centre in the UK. BMC Infectious Disease 2017;17:231-9.

28. Gronhagen RC, Hellstrom PE, Froseth B. Predisposing factors in hepatitis induced by isoniazid rifampicin treatment of tuberculosis. Am Rev Respir Dis 1978;118:161-6.

29. Maria. The impact of anti-tuberculosis drug-induced hepatotoxicity to successful tuberculosis treatment in Indonesia. Asian J Pharm Clin Res 2017;10:194-8.

30. Buntoro IK, Kristin E, Sumardi S. Decrease of liver function after treatment of anti-tuberculosis drugs in tuberculosis patients with malnutrition and alcohol consumption. Int J Pharm Pharm Sci 2016;8:269-73.

31. World Health Organization. Treatment of Tuberculosis Guidelines $4^{\text {th }}$ ed. Geneva: World Health Organization: 2010. Available from: https://www.who.int/tb/publications/2010/9789241547833/en /. [Last accessed on 31 Dec 2020] 